\title{
Some Properties of Large and Small Granules of Waxy Barley (Hordeum vulgare L.) Endosperm Starch
}

\author{
Mitsuko NaKa, ${ }^{1}$ Yoshimi Sugimoto, ${ }^{2}$ Sadao SaKamoto, ${ }^{3}$ \\ and Hidetsugu FUWA ${ }^{1, *}$ \\ ${ }^{1}$ Department of Food and Nutrition, Osaka City University, \\ Sugimoto, Sumiyoshi-ku, Osaka 558, Japan \\ ${ }^{2}$ Department of Home Science, Mukogawa Women's University, \\ Ikebiraki, Nishinomiya 663, Japan \\ ${ }^{3}$ Plant Germ-plasm Institute, Faculty of Agriculture, Kyoto University, \\ Nakajo, Mozume, Muko, Kyoto 617, Japan
}

(Received February 5, 1985)

\begin{abstract}
Summary Large and small starch granules were isolated and characterized from mature barley kernels with waxy endosperms. The large granules of any given waxy cultivar contained more amylose than the small granules of the same cultivar. It was also found that large granules contained a greater amount of long amylopectin B chains and had a lower fraction III : fraction II ratio, one of the structural characteristics of amylopectin, than the small granules in the same cultivar. Small granules showed a wider range of gelatinization and smaller heat of gelatinization by differential scanning calorimetry.
\end{abstract}

Key Words waxy barley starch, endosperm starch, large starch granules, small starch granules, amylose content, chain distribution of amylopectin, gelatinization characteristics, DSC

In a previous study (1), we prepared large and small starch granules from mature grains of 6 cultivars of barley, one with waxy and 5 with non-waxy endosperms, and which showed various differences in structural characteristics and properties between the large and the small granules. Namely, the large granules of any given non-waxy cultivar contained more amylose than the small granules of the same cultivar. Also, large granules contained more long amylopectin B chains and had a lower ratio of fraction III to fraction II of amylopectin (shorter $\alpha$-1,4chains/longer $\alpha$-1,4-chains), one of the structural characteristics of amylopectin, than the small granules. Large granules had a lower conclusion temperature for gelatinization and larger heat of gelatinization than the small granules, as de-

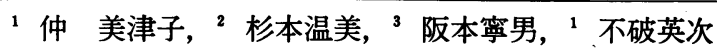

* To whom inquiries should be addressed. 
termined by differential scanning calorimetry (DSC).

The present paper describes the structural characteristics determined by enzymatic and chromatographic methods and the gelatinization characteristics determined by DSC of small and large starch granules prepared from mature kernels of several waxy barley cultivars.

\section{MATERIALS AND METHODS}

1) Barley seeds. Kernel and endosperm types of the 9 cultivars of waxy barley and one cultivar of non-waxy barley which were used are described in Table 1. A single-letter abbreviation was given to the non-waxy cultivar and double- and triple-letter abbreviations were given to waxy cultivars. These abbreviations are used in Tables 2-5 and throughout the text hereafter. All of the cultivars except for NM were grown at the farm of the Plant Germ-plasm Institute, Kyoto University. Sample seeds of NM were kindly provided by Dr. Shinkichi Kubo, Managing Director, Kirin Brewery Co., Ltd., Tokyo, Japan.

Table 1. Kernel and endosperm types of barley sample seeds.

\begin{tabular}{|c|c|c|c|c|}
\hline \multicolumn{2}{|l|}{ Cultivar } & \multirow{2}{*}{$\begin{array}{l}\text { Line } \\
\text { No. }\end{array}$} & \multirow{2}{*}{$\begin{array}{c}\text { Endosperm } \\
\text { type }\end{array}$} & \multirow{2}{*}{$\begin{array}{c}\text { Kernel } \\
\text { type }\end{array}$} \\
\hline Name & Abbreviation & & & \\
\hline Bozu & B & OUJ 180 & nonwaxy & naked \\
\hline Yatomi Mochi & YAM & OUJ 183 & waxy & naked \\
\hline Bozu Mochi & BM & OUJ 467 & waxy & naked \\
\hline Dango Mugi & DM & OUJ 483 & waxy & naked \\
\hline Waxy Oderbrucher & WO & OUJ 485 & waxy & covered \\
\hline Sumire Mochi & SM & OUJ 601 & waxy & naked \\
\hline Tokushima Mochimugi & TM & OUJ 783 & waxy & naked \\
\hline Yonezawa Mochi & YOM & OUJ 784 & waxy & naked \\
\hline Masan Hadakamugi & MH & OUJ 043 & waxy & naked \\
\hline Nijo Mochimugi & NM & - & waxy & covered \\
\hline
\end{tabular}

2) Enzymes. Crystalline Pseudomonas isoamylase [EC 3.2.1.68] was purchased from Hayashibara Biochemical Laboratories, Inc., Okayama, Japan. Sources of glucose oxidase and peroxidase have been reported previously (2).

3) Preparation of barley starch and fractionation of large and small granules. Starch granules were prepared from mature barley grains by Watson's method(3) and purified by Schoch's method(4). Large and small granules were fractionated by a series of decantations as described earlier (1).

4) Other methods. Measurement of starch granular size, determination of iodine absorption spectra, gel filtration of Pseudomonas-isoamylase-debranched materials and differential scanning calorimetry (DSC) have been described elswhere (1). 
Table 2. Average size of large (L) and small (S) starch granules of several waxy and one non-waxy barley cultivars.

\begin{tabular}{lccc}
\hline & \multicolumn{2}{c}{ Average size $(\mu \mathrm{m})$} & \\
\cline { 2 - 3 } Cultivar & L (a) & a/b \\
\hline B & 15.4 & 4.3 & \\
YAM & 15.5 & 3.2 & 3.6 \\
BM & 15.7 & - & 4.8 \\
DM & 14.3 & 3.1 & - \\
WO & 13.7 & 2.7 & 4.6 \\
SM & 14.8 & 2.5 & 5.1 \\
TOM & 14.8 & 2.7 & 5.9 \\
YM & 14.5 & - & 5.5 \\
MH & 17.6 & 2.9 & - \\
NM & 14.0 & 3.3 & 6.1 \\
\hline
\end{tabular}

${ }^{\mathrm{a}}$ For abbreviation, see Table 1.

\section{RESULTS}

1) Average size of large and small starch granules of several waxy barley cultivars

Table 2 shows that the average sizes of large and small granules of waxy barley starch were 14-16 $\mu \mathrm{m}$, except for MH $(17.6 \mu \mathrm{m})$, and 3-4 $\mu \mathrm{m}$, respectively.

2) Absorption spectra of starch-iodine complexes

Some characteristics of the iodine absorption spectra of several waxy barley starches are summarized in Table 3. Large granules showed absorption maxima $\left(\lambda_{\max }\right)$ at $534-556 \mathrm{~nm}$ and small granules at $523-548 \mathrm{~nm}$. The large granules of any given waxy cultivar, each of YAM, BM, DM, WO, SM, TM, YOM, MH and NM, gave a longer $\lambda_{\max }$ and a larger blue value than the small granules of the same cultivar.

\section{3) Elution profiles of debranched waxy barley starches by gel filtration}

Table 4 summarizes the distribution of glucan in each fraction for Pseudomonas-isoamylase-debranched large and small starch granules of non-waxy, B, and 4 waxy barley cultivars, YAM, WO, SM and NM. Because only low yields of small granules were obtained, only the data for large granules are shown for the other 5 waxy cultivars, BM, DM, TM, YOM and MH. The amounts of Fr. I, amylose $(1,5)$, ranged from 3 to $10 \%$ in the large granules and from 1 to $4 \%$ in the small granules of the waxy barley cultivars. The ratio of Fr. III to Fr. II, which represents one of the structural characteristics of amylopectin $(5,6)$, ranged from 3.3 to 3.8 for large granules of the waxy cultivars and from 3.6 to 4.4 for small granules. 
Table 3. Wavelength $\left(\lambda_{\max }\right)$ and optical density at maximum absorbance and blue value of starch-iodine complexes of large (L) and small (S) starch granules of several waxy and one non-waxy barley cultivar.

\begin{tabular}{|c|c|c|c|c|}
\hline Cultivar & $\begin{array}{l}\text { Starch } \\
\text { granules }\end{array}$ & $\begin{array}{l}\lambda_{\max } \\
(\mathrm{nm})\end{array}$ & $\begin{array}{c}\text { Optical density } \\
\text { at } \\
\text { maximum absorbance }\end{array}$ & $\begin{array}{c}\text { Blue value } \\
\text { at } \\
680 \mathrm{~nm}\end{array}$ \\
\hline \multirow{2}{*}{$\mathrm{B}^{\mathrm{a}}$} & L & 588 & 0.502 & 0.389 \\
\hline & $\mathrm{S}$ & 582 & 0.398 & 0.292 \\
\hline \multirow{2}{*}{ YAM } & $\mathrm{L}$ & 537 & 0.301 & 0.122 \\
\hline & $S$ & 527 & 0.238 & 0.077 \\
\hline \multirow{2}{*}{ BM } & L & 556 & 0.343 & 0.193 \\
\hline & $S$ & 548 & 0.285 & 0.154 \\
\hline \multirow{2}{*}{ DM } & L & 534 & 0.284 & 0.102 \\
\hline & S & 526 & 0.216 & 0.072 \\
\hline \multirow{2}{*}{ WO } & $\mathrm{L}$ & 546 & 0.310 & 0.146 \\
\hline & $S$ & 530 & 0.240 & 0.088 \\
\hline \multirow{2}{*}{ SM } & L & 540 & 0.315 & 0.130 \\
\hline & $S$ & 528 & 0.254 & 0.085 \\
\hline \multirow{2}{*}{ TM } & L & 536 & 0.297 & 0.109 \\
\hline & $S$ & 527 & 0.254 & 0.085 \\
\hline \multirow{2}{*}{ YOM } & $\mathrm{L}$ & 537 & 0.292 & 0.109 \\
\hline & S & 523 & 0.245 & 0.075 \\
\hline \multirow{2}{*}{ MH } & L & 540 & 0.308 & 0.128 \\
\hline & $S$ & 528 & 0.225 & 0.077 \\
\hline \multirow{2}{*}{ NM } & L & 544 & 0.308 & 0.140 \\
\hline & $\mathrm{S}$ & 530 & 0.229 & 0.103 \\
\hline
\end{tabular}

${ }^{\text {a }}$ For abbreviation, see Table 1.

4) Pasting characteristics of waxy barley starches by DSC

Table 5 shows the gelatinization characteristics of several waxy barley starches. The small granules of any given cultivar, each of YAM, WO, SM and NM, had a peak temperature for gelatinization $\left(T_{\mathrm{P}}\right)$ similar to that of the large granules of the same cultivar, but had a wider range of gelatinization temperature (from onset $\left(T_{\mathrm{O}}\right)$ to conclusion $\left(T_{\mathrm{C}}\right)$ temperatures) and a smaller heat of gelatinization than the large granules of the same cultivar. 
Table 4. Distribution of Pseudomonas-isoamylase-debranched materials of large (L) and small (S) starch granules of several barley cultivars.

\begin{tabular}{|c|c|c|c|c|c|c|}
\hline \multirow{2}{*}{ Cultivar } & \multirow{2}{*}{$\begin{array}{l}\text { Starch } \\
\text { granules }\end{array}$} & \multicolumn{4}{|c|}{ Distribution of starch materials $(\%)^{\mathrm{a}}$} & \multirow{2}{*}{$\frac{\text { Fr. III }}{\text { Fr.II }}$} \\
\hline & & Fr. I & Int. Fr. & Fr. II & Fr.III & \\
\hline \multirow{2}{*}{$\mathbf{B}^{\mathbf{b}}$} & L & 30.2 & 2.9 & 14.6 & 52.3 & 3.6 \\
\hline & $\mathbf{S}$ & 22.9 & 2.0 & 14.5 & 60.7 & 4.2 \\
\hline \multirow{2}{*}{ YAM } & $\mathrm{L}$ & 5.5 & 4.0 & 18.8 & 71.6 & 3.8 \\
\hline & S & 1.5 & 3.0 & 17.9 & 77.7 & 4.4 \\
\hline \multirow{2}{*}{ WO } & L & 8.2 & 4.0 & 18.1 & 69.7 & 3.8 \\
\hline & $\mathbf{S}$ & 2.8 & 2.9 & 18.4 & 75.9 & 4.1 \\
\hline \multirow{2}{*}{ SM } & $\mathrm{L}$ & 5.4 & 3.2 & 19.2 & 72.2 & 3.8 \\
\hline & $\mathrm{S}$ & 1.1 & 1.9 & 18.8 & 78.2 & 4.2 \\
\hline \multirow{2}{*}{ NM } & $\mathrm{L}$ & 7.2 & 2.6 & 19.0 & 71.2 & 3.7 \\
\hline & $S$ & 3.9 & 2.6 & 20.5 & 73.0 & 3.6 \\
\hline BM & $\mathrm{L}$ & 10.4 & 2.3 & 19.5 & 67.9 & 3.5 \\
\hline $\mathrm{DM}$ & L & 3.0 & 3.0 & 21.2 & 72.8 & 3.4 \\
\hline TM & L & 3.9 & 3.8 & 21.6 & 70.7 & 3.3 \\
\hline YOM & $\mathrm{L}$ & 3.3 & 1.9 & 19.8 & 75.0 & 3.8 \\
\hline MH & $\mathrm{L}$ & 4.4 & 3.3 & 20.0 & 72.3 & 3.6 \\
\hline
\end{tabular}

${ }^{a}$ Each fraction (Fr.) was divided according to the following range of $\lambda_{\max }$ values of iodine-carbohydrate complexes: Fr. I, $\lambda_{\max } \geq 620 \mathrm{~nm}$, Intermediate Fr., $620 \mathrm{~nm}>$ $\lambda_{\max } \geq 600 \mathrm{~nm}$, Fr. II, $600 \mathrm{~nm}>\lambda_{\max } \geq 540 \mathrm{~nm}$ and Fr. III, $540 \mathrm{~nm}>\lambda_{\max }$.

${ }^{\mathrm{b}}$ For abbreviation, see Table 1 .

\section{DISCUSSION}

Large and small starch granules were fractionated by decantation from the mature kernels of 9 waxy and one non-waxy barley cultivars with a known history. In general, small granules represent about $90 \%$ of the total granule number but only $10 \%$ of the weight of the starch (7). Arbitrarily, a large granule is defined as one which has a diameter greater than $10 \mu \mathrm{m}$ (the average value being 14-18 $\mu \mathrm{m}$ ) while a small granule is one which has a diameter less than $10 \mu \mathrm{m}$ (the average value being 3-4 $\mu \mathrm{m})$, according to Banks and Greenwood (8).

Endosperm starches of waxy barley with a known history consisted of $1-10 \%$ 
Table 5. DSC characteristics of large (L) and small (S) starch granules of several barley cultivars. ${ }^{a}$

\begin{tabular}{lccccc}
\hline Cultivar & $\begin{array}{c}\text { Starch } \\
\text { granules }\end{array}$ & $\begin{array}{c}T_{\mathrm{O}} \\
\left({ }^{\circ} \mathrm{C}\right)\end{array}$ & $\begin{array}{c}T_{\mathrm{P}} \\
\left({ }^{\circ} \mathrm{C}\right)\end{array}$ & $\begin{array}{c}T_{\mathrm{C}} \\
\left({ }^{\circ} \mathrm{C}\right)\end{array}$ & $\begin{array}{c}\text { Heat of } \\
\text { gelatinization } \\
(\mathrm{cal} / \mathrm{g})\end{array}$ \\
\hline $\mathrm{B}^{\mathrm{b}}$ & $\mathrm{L}$ & 61 & 63 & 66 & 2.7 \\
& $\mathrm{~S}$ & 59 & 63 & 68 & 1.9 \\
YAM & $\mathrm{L}$ & 62 & 65 & 70 & 3.1 \\
& $\mathrm{~S}$ & 59 & 64 & 70 & 2.3 \\
WO & $\mathrm{L}$ & 59 & 63 & 68 & 2.9 \\
& $\mathrm{~S}$ & 58 & 64 & 72 & 2.0 \\
SM & $\mathrm{L}$ & 60 & 64 & 70 & 3.3 \\
& $\mathrm{~S}$ & 58 & 65 & 73 & 2.0 \\
$\mathrm{NM}$ & $\mathrm{L}$ & 58 & 62 & 65 & 2.8 \\
& $\mathrm{~S}$ & 59 & 64 & 71 & 2.5 \\
\hline
\end{tabular}

${ }^{a} T_{\mathrm{O}}$, onset temperature; $T_{\mathrm{P}}$, peak temperature; $T_{\mathrm{C}}$, conclusion temperature for gelatinization.

${ }^{\mathrm{b}}$ For abbreviation, see Table 1.

amylose according to the enzyme-chromatographic method (Table 4). There are two possible mechanisms for the deposition of amylose in waxy barley (9). In one, the amylose arises from mutation at the amyloplast level. In the other, a direct xenia effect is exerted through cross-pollination in the field, although this possibility seems very unlikely under the experimental conditions adopted in the present study.

Various differences in structural characteristics and properties were observed between the small and large granules of waxy barley starches, as in the case of nonwaxy starches (l). First, the large granules of any given waxy cultivar contained more amylose than the small granules of the same cultivar (Table 4), in agreement with previous findings $(9,10)$. Secondly, the large granules of any given cultivar had a slightly lower Fr. III : Fr. II ratio than the small granules of the same cultivar except in the case of NM (Table 4). Thirdly, the large granules of any given cultivar had a narrower range of gelatinization temperature and a greater heat of gelatinization as determined by DSC than the small granules of the same cultivar.

MacGregor and Morgan(10) recently investigated the fine structures of amylopectins isolated from large and small starch granules of both non-waxy and waxy barley using enzyme-chromatography. The results indicated that amylopectin from large non-waxy starch granules had a slightly higher proportion of long chains compared with the other amylopectins present. However, amylopectins from both large and small granules of waxy barley starch had similar proportions of long 
chains. MacGregor and Morgan concluded that the difference was unlikely to be significant, because of the errors inherent in these determinations.

Bathgate and Palmer (7) reported that the small starch granules isolated from mature barley kernels (cultivar Maris Otter) were far more resistant to gelatinization than the large granules on the basis of polarising microscopy and the adsorption of Cंongo Red dye. Wider ranges of gelatinization and smaller heats of gelatinization of the small granules of waxy barley starches compared with those of large granules were shown by DSC (Table 5), as in the case of non-waxy barley $\operatorname{starch}(1)$.

We have therefore demonstrated differences in structural characteristics and properties between small and large starch granules of mature kernels for at least 4 cultivars of waxy barley with a known history as well as 5 cultivars of non-waxy barley with a known history (1).

This investigation was supported in part by Grants-in-Aid for Scientific Research from the Ministry of Education, Science and Culture of Japan and the Nishin Seifun Foundation.

\section{REFERENCES}

1) Kang, M. Y., Sugimoto, Y., Kato, I., Sakamoto, S., and Fuwa, H. (1985): Some properties of large and small starch granules of barley (Hordeum vulgare L.) endosperm. Agric. Biol. Chem., 49, 1291-1297.

2) Fuwa, H., Nakajima, M., Hamada, A., and Glover, D. V. (1977): Comparative susceptibility to amylases of starches from different plant species and several single endosperm mutants and their double-mutant combinations with opaque-2 inbred Oh43 maize. Cereal Chem., 54, 230-237.

3) Watson, S. A. (1964): Whole starch [1] Corn starch, in Methods in Carbohydrate Chemistry, IV, ed. by Whistler, R. L., Academic Press, Inc., New York, p. 3.

4) Schoch, T. J. (1954): Preparation of starch and the starch fractions, in Methods in Enzymology, III, ed by Colowick, S. P., and Kaplan, N. K., Academic Press, Inc., New York, p. 5.

5) Ikawa, Y., Glover, D. V., Sugimoto, Y., and Fuwa, H. (1981): Some structural characteristics of starches of maize (Zea mays L.) having a specific genetic background. Stärke, 33, 9-13.

6) Asaoka, M., Okuno, K., Sugimoto, Y., and Fuwa, H. (1985): Effect of environmental temperature at the milky stage on amylose content and fine structure of amylopectin of waxy and nonwaxy endosperm starches of rice (Oryza sativa L.). Agric. Biol. Chem., 49, 373-379.

7) Bathgate, G. N., and Palmer, G. H. (1972): A reassessment of the chemical structure of barley and wheat starch granules. Stärke, 24, 335-341.

8) Banks, W., and Greenwood, C. T. (1974): Starch and Its Components, Edinburgh University Press, Edinburgh, pp. 274-284.

9) Banks, W., Greenwood, C. T., and Walker, J. T. (1970): Studies on the starches of barley genotypes: The waxy starch. Stärke, 22, 149-152.

10) MacGregor, A. W., and Morgan, J. E. (1984): Structure of amylopectin isolated from large and small starch granules of normal and waxy barley. Cereal Chem., 61, 222-228.

Vol. 31, No. 4, 1985 